\title{
Влияние двигательной активности на состояние здоровья лиц пожилого возраста
}

\author{
УДК 796.012:37.612 \\ Д. Н. Котко, Н. Л. Гончарук, Л. М. Путро
}

\begin{abstract}
Национальный университет физического воспитания и спорта Украины, Киев, Украина
\end{abstract}

Резюме. Загальмувати старіння можна за допомогою адекватної рухової активності. Рухова активність $€$ фактором профілактики різних хронічних захворювань, збільшення тривалості життя. Мета. Аналіз літератури і результатів власних досліджень щодо особливостей впливу багаторічних фізичних тренувань на фізичну працездатність і стан систем організму у людей похилого віку. Результати. Показано, що у осіб похилого віку, як і в попередні вікові періоди життя, адекватні фізичні навантаження позитивно впливають на системи організму, що дозволяє зберегти фізичну працездатність і збільшити тривалість життя.

Ключові слова. Здорові люди похилого віку, тривалі фізичні тренування.

Motor activity impact on health of the elderly

D. N. Kotko, N. L. Goncharuk, L. M. Putro

National University of Physical Education and Sport of Ukraine, Kyiv, Ukraine

Abstract. It is possible to slow down the age-related changes with the help of adequate motor activity. However, it is necessary to approach the solution of this question not only using physical loads adequate to the functional capabilities of the body, but also taking into account age-related changes in its systems. Objective. Analysis of the literature and the results of own studies with respect to the characteristics of the influence of long-term physical training on physical performance and the state of body systems in healthy elderly people. Results. It is shown that in elderly people as well as in previous age periods of life, adequate physical exertion has a positive effect on the body systems. Motor activity in elderly age as well as in previous age periods of life is a factor of preventing different chronic diseases allowing to maintain physical work capacity and increase life expectancy. Keywords: healthy elderly people, long-term physical training.

Постановка проблеми. Старение - это естественный процесс [4-6, 17, 18, 20, 21, 23, 30]. В литературе имеются данные о возможности замедлить процессы старения с помощью адекватной двигательной активности [30-34]. Двигательная активность является фрактором сохранения здоровья, увеличения продолжительности жизни [3, 4, 13, 15-17, 19-22, 28, 29]. Однако подходить к решению этого вопроса необходимо не только с точки зрения адекватности физической нагрузки, но и с учетом возрастных особенностей индивидуума. К сожалению, при определении двигательного режима для лиц пожилого и старческого возраста не всегда учитываются возрастные особенности организма [5-7, 17-21, 23, 30].
Научно-технический прогресс, глобальные процессы урбанизации современного общества способствуют увеличению физически неактивных лиц и уменьшению фризически активных. Одна из доминирующих особенностей современности ограничение двигательной активности современного человека. На организм человека действует множество раздражителей (температура, солнечная радиация, влажность, производственные вредные воздействия, ограничение двигательной активности и т.п.), которые нарушают постоянство его внутренней среды. Гармоничное существование человека в этих условиях возможно лишь при своевременной приспособительной реакции на воздействия окружающей среды. При увеличении возраста происходят возрастные из- 
менения в органах и системах, которые уменьшают адаптационные возможности организма. В последнее время утвердилась точка зрения, что фризическая рекреация, являющаяся компонентом физической культуры и используемая для повышения адаптационных возможностей и физической работоспособности здоровых людей, может быть не только основой сохранения и улучшения здоровья, но и средством предотвращения и замедления развития процессов старения [1, 2, 7-10, 12, 22].

Цель исследования - анализ литературы и результатов собственных исследований относительно особенностей влияния многолетних физических тренировок на физическую работоспособность и состояние систем организма у лиц пожилого возраста.

Методы и организация исследования. Анализ и обобщение научной, научно-методической литературы и собственных данных. Нами проведено лонгитоюдинальное (в течение 10 лет) наблюдение. Были обследованы 20 здоровых мужчин молодого возраста, 40 здоровых мужчин 60-70 лет, которые за период наблюдения не занимались регулярной двигательной активностью (І группа) и столько же здоровых мужчин такого же возраста, которым назначалась фризическая нагрузка, адекватная фрункциональным возможностям организма (II группа). При определении фрункциональных возможностей организма обследуемых устанавливалась индивидуальная толерантность к фризической нагрузке [15]. Отбор здоровых испытуемых осуществлялся на основании клинических данных, показателей фризической работоспособности, изучения показателей функционирования систем организма. Оценивалась динамика показателей у обследуемых разных групп фризической работоспособности и функционирования систем организма (системи дыхания, кровообращения и др.).

Результаты исследования. Согласно научным данным, уровень физической работоспособности и ряд показателей, ее характеризующих, в процессе старения снижается [23, 25-28].

Существуют научные данные, которые показывают отсутствие отличий в снижении этих показателей между мужчинами и женщинами в процессе старения [14].

Возрастные изменения работоспособности обусловлены регуляторными фракторами. К этим фракторам относятся: ослабление трофрических влияний симпатической нервной системы на скелетные мышцы, фрункциональных и органических изменений центральной и периферической нервной системы [17, 18, 24].

Согласно данным проведеннного нами многолетнего наблюдения с повторным обследованием лиц старших возрастных групп, не занимающихся и занимающихся двигательной активностью показано следующее. Физическая работоспособность здоровых мужчин пожилого возраста в 2 раза меньше, чем работоспособность здоровых мужчин молодого возраста. Физическая работоспособность и $\dot{\mathrm{V}} \mathrm{O}_{2} \max$ у фризически неактивных мужчин старшего возраста постепенно снижается. В I группе фризическая работоспособность и $\mathrm{VO}_{2}$ max стали меньше (на10 \%). Во II группе эти показания не изменились. Они снижались у обследованных I группы в среднем на $1 \%$ за год, что согласуется с результатами других исследователей $[9,25]$. Это уменьшение в основном связано со снижением кардиореспираторной выносливости, во многом зависящей от центрального и периферического кровообращения [16, 18, 24].

Таким образом, несмотря на увеличение возраста при двигательной активности старение не

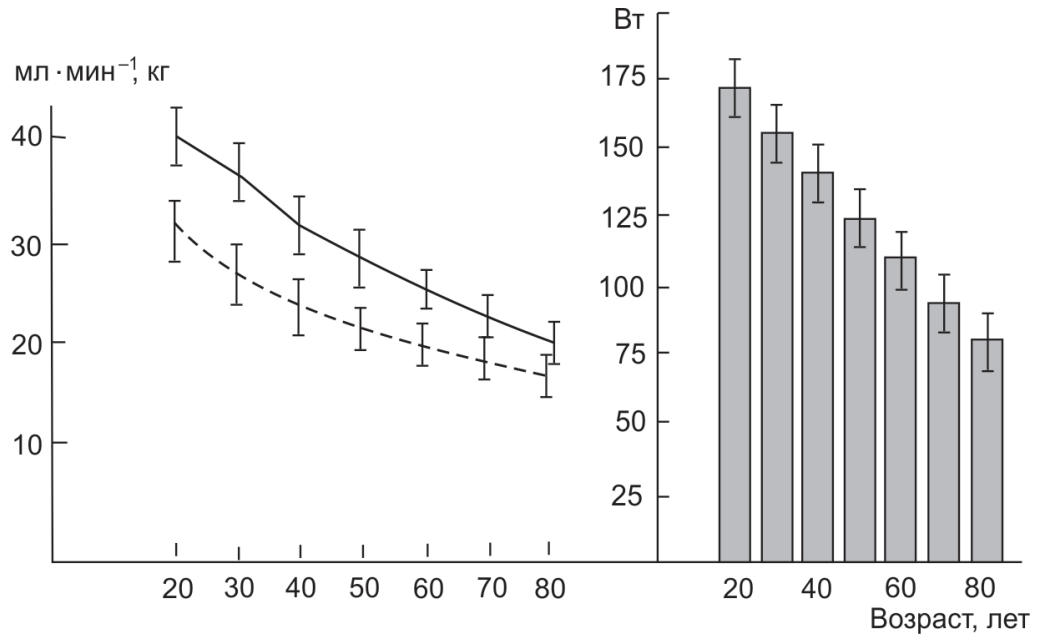

Рисунок 1 - Потребление кислорода (-), порог анаэробного обмена (-- -) и мощность субмаксимальной нагрузки в различные возрастные периоды $(\square)[14]$ 
обязательно предопределяет уменьшение фризической работоспособности и анаэробных возможностей. При многолетних адекватных физических тренировках значительного снижения физической работоспособности и $\dot{\mathrm{V}}_{2} \max$ у обследованных нами лиц пожилого возраста не наблюдалось.

Согласно нашим данным, степень уменьшения $\dot{\mathrm{V}} \mathrm{O}_{2} \max$ у пожилых фризически активных лиц значительно меньше снижения его у малоподвижных.

Снижение физической работоспособности с возрастом в значительной мере связано с ухудшением фрункции легких, которая значительно изменяется [7-11, 13]. Как ранее указывалось нами, начиная с 30-летнего возраста происходит линейное снижение жизненной емкости легких. Таким изменениям отвечают изменения максимальной вентиляции при физической нагрузке. Максимальная экспираторная вентиляция $\left(\mathrm{V}_{\text {Емакс }}\right)$ возрастает к достижению физической зрелости и потом с возрастом снижается. У мужчин $\mathrm{V}_{\text {Емакс }}$ увеличивается до $140 \pi \cdot$ мин $^{-1}$ к 40 годам и снижается до 60-80 л мин $^{-1}$ к 60-70 годам. Подобная структура характерна и для женщин, за исключением того, что абсолютные показатели у них ниже, очевидно, вследствие меньших размеров тела.

Подобные изменения фрункции легких у физически малоактивных мужчин и женщин, вероятно, обусловлены рядом фракторов. Самый важный из них - потеря или снижение с возрастом эластичности легочной ткани и грудной клетки, которые ведут к увеличению объема работы при дыхании. Малоподвижность грудной клетки, очевидно, является главной причиной ухудшения функции легких. Вместе с тем, несмотря на все эти изменения, легкие, как и раньше, имеют большой резерв и сохраняют адекватную дифрфузионную способность.

Длительные фризические тренировки у лиц старшего возраста уменьшают степень ухудшения эластичности легких и грудной клетки. В результате этого у лиц пожилого возраста, которые занимались фризическими тренировками, легочная вентиляция снижена незначительно. Сниженный уровень аэробных способностей у них не является результатом изменений внешнего дыхания. Кроме того, при значительной фризической нагрузке фризически активные лица и лица старшего возраста могут достигать почти максимального (97 \%) насыщения кислородом артериальной крови.

С возрастом меняется фрункция сердечно-сосудистой системы. Одним из важных изменений вследствие процесса старения является снижение $4 \mathrm{CC}_{\text {макс }}$. Если у молодых она нередко пре- вышает 200 уд $\cdot$ мин $^{-1}$, то у 60 -летних здоровых лиц пожилого возраста она составляет около 160 уд мин $^{-1}$. При этом отмечается снижение ЧСС макс приблизительно на 1 уд $\cdot$ мин $^{-1}$ за год.

Снижение $4 \mathrm{CC}_{\text {макс }}$ с возрастом одинаковое как у малоподвижных, так и у хорошо тренированных людей. Например, ЧСС пожилых фризически активных мужчин такая же, как у фиизически активных такого же возраста, которые продолжают заниматься двигательной активностью. Уменьшение ЧСС макс очевидно, вызвано морфологическими и фрункциональными изменениями в проводящей системе сердца, особенно в синусовом узле и пучке Гисса. Кроме того, имеет место сниженная чувствительность бета-1-адренорецепторов к стимуляции катехоламинами [1]. С возрастом и у фризически активных лиц снижаются максимальный систолический объем и сердечный выброс. У фризически активных пожилых лиц старшего возраста максимальный сердечный выброс был на $5 \pi \cdot$ мин $^{-1}$ $(21 \%)$ меньше, чем у лиц молодого возраста. Это отличие обусловлено более низкой ЧСС макс и уменьшенным систолическим объемом у лиц пожилого возраста. Уменьшению систолического объема у пожилых физически активных лиц обычно сопутствует некоторое повышение перифрерического сосудистого сопротивления. Вместе с тем при сравнении с малоподвижными мужчинами такого же возраста у лиц пожилого возраста МОК был намного выше вследствие большего систолического объема и, таким образом, большего максимального сердечного выброса.

Периферический кровоток, согласно нашим данным, снижается с возрастом, несмотря на то, что плотность капилляров может не меняться [20]. У лиц пожилого возраста периферическое сосудистое сопротивление (ПСС) на высоте максимальной нагрузке примерно в 3 раза выше, чем у молодых (1733 и 611 дин $/\left(\mathrm{c}^{\cdot} \mathrm{cm}^{-5}\right)$ соответственно. Эта особенность связана как с морфологическими изменениями артериальных сосудов и артериол, так и с изменением регуляции их тонуса. У лиц пожилого возраста кровоснабжение работающих мышц при той же интенсивности работы на 10-15\% ниже, чем у хорошо подготовленных молодых спортсменов. Однако снижение кровоснабжения мышц ног у лиц пожилого возраста компенсируется высшей АВР по $\mathrm{O}_{2}$ (мышцы извлекают больше кислорода). Вследствие этого, несмотря на разную степень кровоснабжения работающих мышц, утилизация ими кислорода при субмаксимальной интенсивности работы оказывется одинаковой у молодых и у лиц пожилого возраста [13]. 
С возрастом артерии и артериолы теряют эластичность и способность расширятся [20]. Это касается прежде всего сосудов эластического типа. Периферическое сосудистое сопротивление при этом повышается как в покое, так и при выполнении фризической нагрузки. У пожилых спортсменов среднее артериальное давление несколько ниже, чем у большинства мужчин такого же возраста, которые ведут малоподвижный образ жизни. Периферическое сопротивление у них выше, чем у молодых спортсменов, систолический объем крови несколько меньше, чем у молодых спортсменов.

Постепенное уменьшение максимального сердечного выброса и потребления кислорода у фризически активных лиц пожилого возраста является результатом ухудшения насосной способности сердца и снижения периферического кровотока. Обобщение вышеуказанных данных приводит к выводу: процесс старения снижает функцию дыхательной и сердечно-сосудистой систем, выносливость, тем самым ухудшает физическую работоспособность, особенно при снижении двигательной активности.

Снижение $\dot{\mathrm{O}}_{2} \max$ с возрастом и в результате недостаточной двигательной активности в основном обусловлено снижением ЧСС симального систолического объема и $\mathrm{ABP}^{\text {макс }}$ по $\mathrm{O}_{2}$.

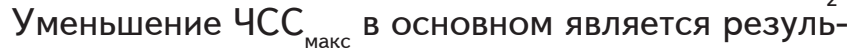
татом снижения активности симпатической нервной системы и изменения системы проводимости сердца. Уменьшение систолического объема вызвано главным образом повышенным общим перифрерическим сопротивлением сосудов вследствие сниженной с возрастом эластичности артерий, а также снижением сократительной способности левого желудочка. Снижение АВР по $\mathrm{O}_{2}$, связанно со снижением кровоснабжения активных мышц, вероятно, вследствие уменьшения сердечного выброса.

Уровень силы, необходимый для осуществления повседневной деятельности, не меняется на протяжении всей жизни. Вместе с тем уровень максимальной силы, которая превышает уровень силы, необходимой для осуществления повседневной деятельности, с возрастом постепенно снижается. Например, способность вставать из положения сидя ухудшается в возрасте 50 лет, а в 80 лет некоторые люди не в состоянии этого сделать. Лица пожилого возраста, как правило, могут выполнять работу, которая не требует больших мышечных усилий [18].

Возрастное снижение силовых качеств обусловлено главным образом значительным уменьшением мышечной массы вследствие процесса старения или сниженного уровня двигательной активности [18]. У лиц пожилого возраста, которые ведут малоподвижный образ жизни, наблюдается значительное уменьшение мышечной массы и увеличение количества подкожного жира.

Результаты исследований влияния процесса старения на состав медленносокращающихся (МС) и быстросокращающихся (БС) волокон довольно противоречивы. Результаты исследований четырехглавой мышцы бедра у умерших в возрасте 15-83 года свидетельствуют, что тип волокон не меняется на протяжении всей жизни. Это также подтвердили исследования молодых и пожилых спортсменов. Вместе с тем исследования, проведенные на одних и тех же спортсменах с интервалом в 18 лет, показывают, что количество или интенсивность фризических занятий или, скорее, и первое, и второе, могут играть важную роль в перераспределении с возрастом типа мышечных волокон. Пробы, взятые из икроножной мышцы с помощью пункционной биопсии в группе сильнейших бегунов на длинные дистанции, показали, что при сохранении интенсивности и продолжительности нагрузки состав мышечных волокон не меняется на протяжении 18-летнего периода. Вместе с этим при снижении уровня мышечной деятельности или при прекращении занятий вообще часть МС-волокон увеличивается. Хотя влияние процесса старения на состав мышечных волокон еще недостаточно выяснено, считается, что у физически активных лиц с возрастом увеличивается и часть МС-волокон. Эти данные указывают, что стимулирование мышц (их активности) играет важную роль в распределении типа волокон с возрастом.

Предполагают, что увеличение количества МС-волокон вызвано уменьшением числа БС-волокон, вследствие чего соотношение меняется в сторону первых. Неясно также, чем вызвано сокращение числа БС-волокон. Предполагают, что с возрастом уменьшается количество быстро сокращающихся нейронов. Неиннервированные мышечные волокна постепенно атрофируются и абсорбируются организмом.

Результаты многих исследований показывают уменьшение количества и размеров мышечных волокон с возрастом. После 50 лет общее число мышечных волокон сокращается на $10 \%$ каждые 10 лет. Это частично может объяснить возникновение мышечной атрофрии с возрастом. Кроме того, в процессе старения уменьшается размер как МС-, так и БС-волокон. Этому противодействуют физические тренировки.

Установлено также, что процесс старения сопровождается значительными изменениями 
способности нервной системы обрабатывать информацию и активировать мышцы. С возрастом замедляется выполнение простых и сложных движений, вместе с тем фризически активные лица пожилого возраста выполняют эти движения лишь немного медленнее, чем молодые [23, 24].

Указанные нервно-мышечные изменения в процессе старения, в определенной степени, предопределяют снижение силовых способностей и выносливости; вместе с тем активное занятие фризическими тренировками уменьшает степень влияния процесса старения на эти изменения. Это не значит, конечно, что регулярные фризические тренировки могут остановить процесс биологического старения, они могут лишь уменьшить многочисленные негативные влияния на фризическую трудоспособность.

Установлено, что, несмотря на уменьшение мышечной массы у стареющих мужчин, ее качество остается почти таким же. Количество капилляров на единицу площади одинаково у бегунов на длинные дистанции молодого и пожилого возраста. Активность окислительных ферментов в мышцах спортсменов пожилого возраста, которые занимаются циклическими видами спорта, всего на 10-15\% меньше, чем в мышцах молодых спортсменов. Таким образом, окислительная способность скелетных мышц у спортсменов пожилого возраста, которые занимаются циклическими видами спорта, лишь ненамного ниже, чем у молодых сильных бегунов. Это свидетельствует о том, что процесс старения незначительно влияет на адаптацию скелетной мышцы к нагрузкам, направленным на развитие выносливости.

Силовые способности в процессе старения подвергаются изменениям. С возрастом уровень силовых способностей неизбежно снижается. В результате образ жизни становится менее подвижным, что, в свою очередь, ведет к еще большему снижению уровня силовых способностей и, следовательно, к все менее подвижной жизни. Естественно, что снижение уровня силовых способностей повышает риск падений (например, около $40 \%$ населения в возрасте 65 лет и старше падают хотя бы раз в год). Даже сам страх падения значительно ограничивает уровень деятельности человека, что ведет к изоляции от общества, снижению уровня двигательной активности и, в конечном итоге, к зависимости от окружающих.

При старении наблюдается естественное снижение мышечной силы. В 30 лет мы, как правило, достигаем пика мышечной силы, а затем, если не предпринимаем никаких мер, уровень мышечной силы постепенно снижается. К 85 годам уровень снижения достигает порядка 50 \%. У женщин такое снижение происходит менее заметно. Этот фракт, очевидно, можно объяснить следующим. Мужчины после выхода на пенсию, как правило, начинают вести малоподвижный образ жизни, тогда как женщины по-прежнему выполняют большой объем работы по дому и поэтому продолжают оставаться активными.

Снижение уровня мышечной силы с возрастом, в принципе, нормальное явление (даже у тренированных спортсменов в пожилом возрасте снижается уровень мышечной силы). Следует отметить, что включение в программу занятий упражнений силовой направленности приводит к тому, что лица пожилого возраста, даже те, кто в течение многих лет вели малоподвижный образ жизни, фризическими тренировками достигают значительного прироста силы, замедляя тем самым снижение уровня мышечной силы, обусловленное процессом старения.

Процесс деминерализации обычно начинается в возрасте 30 лет. Примерно у $90 \%$ населения старше 75 лет наблюдаются явные признаки деминерализации костей. Остеопорозом страдают как мужчины, так и женщины, однако процесс деминерализации у женщин протекает в два раза быстрее, переломы вследствие остеопороза встречаются также в два раза чаще. К 80 годам у 1/6 мужчин и 1/3 женщин возникают травмы бедра. Более интенсивное течение процесса деминерализации костей у женщин связано, повидимому, с гормональными изменениями, которые происходят после менопаузы, когда интенсивность деминерализации резко увеличивается [18]. У мужчин, вступающих в зрелый возраст, кости более длинные и плотные, поэтому процесс деминерализации у них длится дольше. В этой связи напрашивается вывод: для профилактики остеопороза необходимо повышать плотность костей с юного возраста, используя фризические упражнения и соответствующий режим питания. Эфрфективными можно считать те, которые способствуют развитию силы. Плавание и езда на велосипеде, когда масса тела поддерживается, по-видимому, недостаточно эфрфективны.

Поскольку кости реагируют повышением плотности на нагрузки, к которым не привыкли, они должны быть достаточно высокими, чтобы стимулировать этот процесс. Вместе с тем лица, давно страдающие остеопорозом, должны осторожно подходить к фризическим нагрузкам, проконсультировавшись предварительно с врачом. Физические нагрузки, особенно виды де- 
ятельности силовой направленности, не только повышают плотность костей, но и способствуют увеличению мышечной силы, необходимой для обеспечения устойчивости, что снижает риск падений и, следовательно, переломов. Кроме того, увеличение мышечной массы, силы и гибкости вследствие занятий фризическими упражнениями снижает риск травмы даже при падении. Плотность костей повышается только в тех участках, которые подвергаются нагрузкам. Так, бег трусцой может привести к увеличению плотности костей ног и, в меньшей степени, нижней части позвоночника, но не костей рук или верхней части позвоночника. Поэтому необходимо включать фризические упражнения для всего тела.

- Регулярность фризических тренировок играет большую роль. Даже при относительно коротких периодах бездеятельности кости начинают терять кальций.

- Потребление кальция имеет большое значение для нормального состояния костей. Взрослым (старше 25 лет) рекомендуется ежедневно потреблять 800 мг кальция, хотя, согласно рекомендациям Национальной организации по проблемам остеопороза, эта доза должна быть выше - 1000 мг, а женщинам с наступлением климакса рекомендуется потреблять до 1500 мг.

- Использовать кальциевые добавки следует с осторожностью. Их применение оправдано, если женщина ограничивает потребление молочных продуктов с тем, чтобы сбросить лишний вес. Потребление кальция неэффективно, если только в организме не содержится достаточное количество витамина D. Организм производит витамин D при пребывании на солнце. В организме лиц пожилого возраста, которые редко бывают на солнце, а также жителей севера вряд ли имеется достаточное количество этого витамина.

Трудно сказать, насколько эффективно потребление кальция либо его добавок, если человек ведет малоактивный образ жизни. Вряд ли

\section{Литература}

1. Булатова ММ, Усачов ЮО. Сучасні фозкультурно-оздоровчі технології у фізичному вихованні [Modern health-improving technologies in physical education]. У кн.: Круцевич Т.Ю., редактор. Теорія і методика фізичного виховання. Т.2 Київ: Олімпійська література; 2008. С. 320-54.

2. Галимов ГЯ. Пожилой возраст и двигательная активность. [E/derly and physical activity]. Улан-Уде: Издательство БГСХА; 2005. 128 с.

3. Ильницкий АН, Ивко КО, Фадеева ПА, Полторацкий АН. Оценка когнитивной функции и качества жизни пожилых людей, связанного со здоровьем, под влиянием аэробных и анаэробных тренировок [Assessment of the cognitive function and quality of life of older people related to health under the influence of aerobic and anaerobic training] Научный результат. Медицина и фрармация. 2018; 4, 1:16-26.

4. Коркушко ОВ. Клиническая кардиология в гериатрии [Clinical Cardiology in Geriatrics]. Москва: Медицина; 1980. 288 с. потребление кальция принесет пользу без выполнения фризических упражнений.

С возрастом увеличивается частота развития артритов. Артрит - воспаление суставов, сопровождающееся болями, иногда структурными изменениями. Наблюдается вполне очевидная взаимосвязь между процессом старения и артритом. К 60 годам у большинства людей появляются симптомы артрита - ригидность суставов по утрам, их опухание. Это в значительной степени снижает качество жизни. Артрит, подобно большинству других заболеваний, которые мы связываем с процессом старения, приводит к образованию замкнутого круга: боль - снижение уровня двигательной активности - повышенная болезненность - ускорение процесса старения. Регулярные занятия фризическими упражнениями уменьшают риск развития многих серьезных заболеваний суставов у лиц старшего возраста.

\section{Выводы}

1. Уровень аэробных способностей обычно снижается на $10 \%$ за 10 лет у относительно малоподвижных мужчин.

2. Следует отметить, что уменьшение $\dot{\mathrm{V}} \mathrm{O}_{2} \max$ в процессе старения может быть не совсем точным при его соотношении с массой тела, поскольку с возрастом масса тела, как правило, увеличивается, вследствие чего показатели $\dot{\mathrm{VO}}_{2} \max$ оказываются ошибочно сниженными. Кроме того, при таком подходе не учитывается начальный показатель $\dot{\mathrm{VO}} 2 \mathrm{max}$.

3. Целесообразно проводить сравнение, ориентируясь на процентные изменения $\dot{\mathrm{V}}_{2} \max$.

4. Исследования физически активных лиц пожилого возраста и фризически неактивных лиц того же возраста показывают, что уменьшение $\dot{\mathrm{V}} \mathrm{O}_{2} \max$ не является следствием только возраста. У спортсменов, которые продолжают интенсивно тренироваться, уровень снижения $\dot{\mathrm{V}}_{2} \max$ выражен значительно меньше.

5. Коркушко ОВ, Калиновская ЕТ, Молотков ВИ. Преждевременное старение человека [Premature aging]. Киев: Здоровья; 1979. 192 с.

6. Коркушко ОВ, Ярошенко ЮТ. Вікова динаміка критичних рівнів фізичного навантаження у практично здорових чоловіків за даними поперечних спостережень [Age-related dynamics of critical levels of exercise in healthy men according to cross-sectional data]. Фізіологічний журнал. 2004; 50, 1:39-45.

7. Коркушко О.В, Ярошенко ЮТ, Чеботарев НД, Писарук АВ Максимальная рабочая производительность системы внешнего дыхания и газообмена у практически здоровых лиц в различные возрастные периоды [Maximum working productivity of the system of external respiration and gas exchange in practically healthy persons at different ages]. Укр. пульмон. журнал. 2001;4:12-6.

8. Коркушко ОВ, Ярошенко ЮТ. Максимальная гемодинамическая производительность у практически здоровых лиц в различные возрастные 


\section{Спортивна медицина і фізична реабілітація, № 1, 2020}

периоды [Maximum hemodynamic performance in healthy individuals at different age periods]. Укр. кардиол. журн.2002; 2: 83-9.

9. Коркушко ОВ, Ярошенко ЮТ. Значимость факторов гемодинамики в возрастном снижении максимального потребления кислорода [Significance of hemodynamic factors in age-related decrease in maximum oxygen consumption]. Кровообіг та гемостаз. 2010; 1/2: 5-28.

10. Коркушко ОВ, Шатило ВБ, Ярошенко ЮТ, Шатило ТВ. Динамика ритма сердца в переходных процессах при физических нагрузках у здоровых людей разного возраста [Dynamics of the heart rhythm in transients during exercise in healthy people of different ages]. Физиол. журн.; 1989; 35, 3: 38-42.

11. Коркушко ОВ, Шатило ВБ, Ярошенко ЮТ, Фролькис МВ, Писарук АВ, Антонюк-Щеглова ИА. Особенности реакции организма людей пожилого возраста на стрессорное воздействие (физическую нагрузку) [Features of the reaction of the body of the elderly to stress exposure (physical activity)]. Проблемы старения и долголетия. 1993; 3, 3: 184-91.

12. Коркушко ОВ, Ярошенко ЮТ, Писарук АВ, Шатило ВБ. Комплексная оценка функционального состояния организма у лиц старших возрастных групп по данным нагрузочного тестирования [Comprehensive assessment of the functional state of the body in people of older age groups according to stress testing]. Проблемы старения и долголетия. 2002; 11, 4: 370-80.

13. Коркушко ОВ, Иванов ЛА. Гипоксия и старение [Hyрохіа and aging]. Киев: Наук. думка; 1980. 274 с.

14. Коркушко ОВ, Чеботарев ДФ, Калиновська ЕГ. Гериатрия в терапевтической практике [Geriatrics in therapeutic practice]. Киев: Здоров'я; 1993.840 с.

15. КоткоДН, ГончарукНЛ. Особенностипроведенияпробыс физической нагрузкой для оценки физической работоспособности спортсменов старшего возраста [Features of a physical exercise test to assess the physical performance of older athletes]. Материалы III Международной научно-практической конференции "Сучасні проблеми теорії та практики фізичного виховання, спортивних дисциплін і туризму“ 16 грудня 2016 року: 43-6.

16. Котко ДМ, Гончарук НЛ, Путро ЛМ, Шевцов СМ. Рухова активність як важливий фактор мотивації до населення до здорового способу життя [Activity is an important factor of motivation to the population to a healthy way of life]. Науковий часопис Національного педагогічного університету ім. М. П. Драгоманова. Сер. 15. «Науково-педагогічні проблеми фізичної культури /Фізична культура і спорт. 2019. Вип 4 (112) 19: 57-61.

17. Котко ДМ, Гончарук НЛ, Путро ЛМ, Томчук ИС. Особенности реакции кардио-респираторной системы на физическую нагрузку у людей старшего возраста [Features of the reaction of the cardio-respiratory system to physical activity in older people]. Спортивна медицина та фрізична реабілітація. 2018; 2: 45-53.

18. Лазебник ЛБ. Практическая гериатрия (Избранные клинические и организационные аспекты) [Practical Geriatrics (Selected Clinical and Organizational Aspects)]. Москва; 2002. 556 с.

19. Милькаманович ВК. Геронтология и гериатрия [Gerontology and geriatrics]. Мастацкая литература; 2010. 280 c.

20. Назар ПС, Котко ДН, Шевченко ЕА, Левон М.М. Возрастные особенности двигательной активности [Age features of physical activity: a training manual]. Навчальний посібник Київ: ООО «Издательство «Сталь»; 2014. 232 c.
21. Погодина АБ, Газимов АХ. Основы геронтологии и гериатpuи [The basics of gerontology and geriatrics]. Москва: Медицина; 2007. $256 \mathrm{c}$.

22. Прощаев КИ, Ивко КО, Фадеева ПА, Полторацкий АН. Оценка двигательной активности и состояния мышечной функции у людей пожилого возраста в процессе применения аэробных и анаэробных тренировок [Assessment of motor activity and the state of muscle function in elderly people in the process of aerobic and anaerobic training]. Научный результат. Медицина и фрармация. 2018; 4, 1, $27-38$.

23. Уилмор ДжХ, Костилл Д. Физиология спорта и двигательной активности [Physiology of sports and physical activity]. Киев: Олимпийская литература; 1997.503 с.

24. Фролькис ВВ, Безруков ВВ, Шевчук ВГ. Кровоснабжение и старение [Blood supply and aging]. Л.: Наука; 1984. 215 с.

25. Ярошенко ЮТ, Коркушко ОВ. Возрастная динамика максимального потребления кислорода у практически здоровых мужчин пожилого возраста с различным уровнем двигательной активности по данным лонгитудинального наблюдения [Age-related dynamics of maximum oxygen consumption in practically healthy elderly men with different levels of motor activity according to longitudinal observation]. Проблемы старения и долголетия. 1995; 5, 1-2: 56-65.

26. Ярошенко Ю.Т. Оценка фрункционального состояния систем гемодинамики и газообмена по результатам пробы с физической нагрузкой малой мощности как показатель биологического возраста человека [Assessment of the functional state of hemodynamic and gas exchange systems based on the results of tests with physical activity of low power as an indicator of the biological age of a person]. Проблемы старения и долголетия. 1992; 3: 289-92.

27. Ярошенко ЮТ, Писарук АВ. Влияние физических тренировок на вариабельность ритма у здоровых людей пожилого возраста [The effect of physical training on rhythm variability in healthy elderly people]. Проблемь старения и долголетия. 2003; 12, 3: 265-71.

28. Amudsen LR., Devahl JM., Ellingham C. Evaluation of a drop exercise program for elderly women. Phys. Ther. 1989; 69. 6; 475-480.

29. Arakawa K. Beneficial effects of physical exercise. Clin. and Exp. Hypertens. 2000; 22, 4: 331.

30. Bunc V, Stilec M. Walking like a tool of body composition and aerobic fitness improvement in senior women. "People, sport and health": III Intern. congress. 2007. SPb, 175.

31. Collis CM, Mallier AT. Government policy and the provision of training for older workers "Gerontechnology": Second Intern. Confer., Helsinki, 1996. P. 78.

32. Kafandari V, Mavragani T, Zigouri E, et al. The effect on physical activity in the bone mass and fi tness in middle aged and elderly women. "People, sport and health": III Intern.congress. SPb, 2007. P.184.

33. Kyriazi Ch, Michalopoulou M, Zisi V, et al. Th e effect on physical activity and age to simple reaction time in Greek older adults. "People, sport and health": III Intern.congress. SPb, 2007. P.186.

34. Narici MV., Giuff reda L, Baldi M, et al. Unique features of workinduced skeletal muscle hypertrophy in elderly humans. J. Physiol. Proc. 2000; 526: 35-6.

35. Robinson S. Experimental Stadies of physical fitness in relation to age. - "Arbeitsphysiologie". 1938; 3: 251-323.

Надійшла 17.02.2020 